\title{
Development and Social Implementation of Smartphone App Nige-Tore for Improving Tsunami Evacuation Drills: Synergistic Effects Between Commitment and Contingency
}

\author{
Katsuya Yamori $^{1} \cdot$ Takashi Sugiyama $^{1}$
}

Accepted: 22 October 2020/Published online: 1 December 2020

(C) The Author(s) 2020

\begin{abstract}
This research explored how we can improve tsunami evacuation behavior, which has been a major social issue since the 2011 Great East Japan Earthquake and Tsunami. We introduce Nige-Tore, a smartphone app for supporting tsunami evacuation drills, which was developed within an interdisciplinary research framework. Nige-Tore serves as an effective interface tool that successfully visualizes the dynamic interactions between human actions (evacuation behavior) and natural phenomena (tsunami behavior). Drill participants can check, on their smartphone, the estimated inundation area of the approaching tsunami, along with their own current evacuation trajectory. The results of real-world trials using NigeTore show that the app is more powerful than conventional devices and methods that have been used in tsunami evacuation training, such as hazard maps and traditional drills that do not make use of any apps, because Nige-Tore provides an interface that enables commitment and contingency thinking - which at first glance appear to represent different orientations- to not only coexist but to synergize. "Commitment" (devotion or involvement) refers to the act of immersing oneself in and viewing as absolute one particular scenario or its potential to be actualized, given conditions in which infinite scenarios may be actualized, depending on the interactions between human systems and natural systems. "Contingency" thinking (an accidental or incidental state) refers to the act of relativizing and separating oneself from any particular scenario or its potential to be actualized, given the same
\end{abstract}

Katsuya Yamori

momo-san@mx5.canvas.ne.jp

1 Disaster Prevention Research Institute, Kyoto University, Kyoto 611-0011, Japan conditions. The synergistic effect of "commitment" and "contingency" thinking also expands people's capacity to cope with unexpected and unforeseen events.

Keywords Commitment · Contingency

thinking $\cdot$ Evacuation behavior $\cdot$ Japan $\cdot$ Smartphone app · Tsunami

\section{Tsunami Evacuations: Interactions Between Human Systems and Natural Systems}

Tsunamis are among the most harmful types of natural hazards, as illustrated by the catastrophic 2011 Great East Japan Earthquake and Tsunami, which killed around 2800 people, and the 2004 Indian Ocean Tsunami, which killed over 225,000 people. Tsunami countermeasures are particularly important for Japanese society today, as the risk increases for a massive earthquake in the Nankai Trough, which is expected to severely impact central and western Japan (Cabinet Office, Government of Japan 2015a). The probability of such an earthquake occurring in the next 30 years is $70-80 \%$, and in a worst-case scenario is anticipated to result in over 320,000 fatalities nationwide (approximately 230,000 , or $72 \%$, of which would be due to the tsunami). These figures far exceed the damage from the Great East Japan Earthquake and Tsunami. The expected height and arrival time of the tsunami will vary widely in different regions. The tsunami height is expected to be less than $1 \mathrm{~m}$ in areas far from the subduction zone in the Pacific, such as the greater Osaka metropolitan area, while it might be more than $30 \mathrm{~m}$ in areas directly facing the Pacific Ocean, such as towns and cities in Kochi Prefecture. The time before the tsunami arrives may also range 
from only a few minutes in Wakayama or Kochi to around $2 \mathrm{~h}$ in Osaka (Fig. 1).

The government's basic framework for responding to a large disaster of this type (Cabinet Office, Government of Japan 2015a) divides tsunamis into two categories based on size-Level 1: tsunamis that occur relatively frequently at a scale that has been experienced in the past; and Level 2: the largest-scale tsunamis imaginable. The response to the former relies primarily on "hard" infrastructure, while response to the latter relies primarily on "soft" infrastructure. In simple terms, this approach aims to prevent Level 1 tsunamis from reaching residential areas through the use of seawalls and similar infrastructure, but declares escape (rapid evacuation) the only feasible response to Level 2 tsunamis. The national government is also working on teaching the public that "rapid evacuation is the first thing you should do to protect yourself from a tsunami" (Cabinet Office, Government of Japan 2015b, p. 4).

Thus far, two main approaches have been taken for improving evacuation behavior, which is viewed as the most important tsunami countermeasure. The first is a human-systems (human behavior) approach focused on evacuation drills and similar methods used in the past (Sun et al. 2013, 2014b). The second is a natural-systems (tsunami behavior) approach focused on creating and publicizing tsunami hazard maps that indicate the anticipated areas of maximum inundation, developing warning systems that alert people to the scale of tsunamis during emergencies, and similar measures (Japan Meteorological Agency 2013).

A significant problem, however, is that these two approaches have thus far been implemented in isolation from one another. Setting aside the issue of stagnant participation rates and motivation for evacuation drills, such drills are frequently implemented without adequate

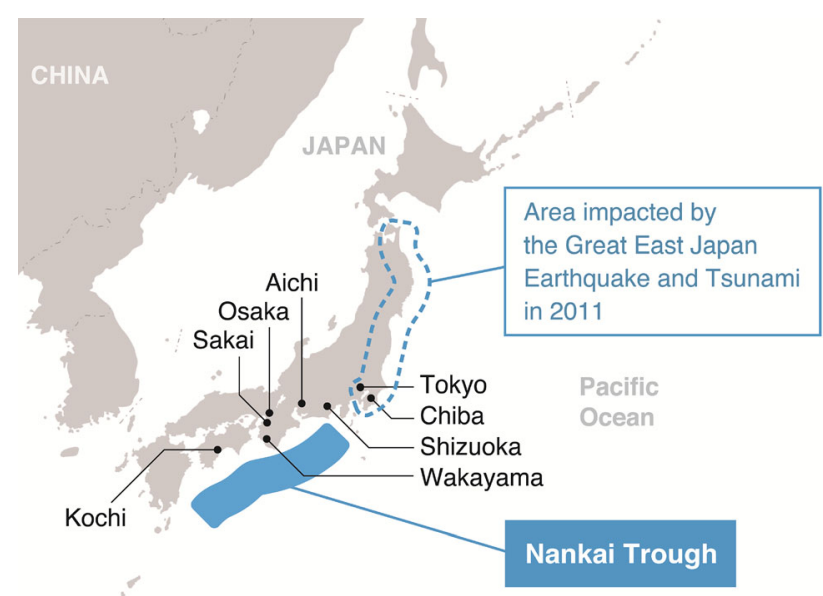

Fig. 1 The area impacted by the 2011 Great East Japan Earthquake and Tsunami, location of the Nankai Trough, and cities and prefectures where field experiments were conducted in this study reference to actual tsunami behavior, such as when elementary students practice evacuating from their classroom to an elevated location designated by the municipal government but are instructed to take the same route every time. It is true that this routine-type drill is not always useless, but overdependence or over-fixation on a prescribed drill scenario without taking changeability of actual tsunami hazards into consideration was strongly blamed for the tragically huge loss of human lives during the 2011 Great East Japan Earthquake and Tsunami. Similarly, setting aside the fact that distribution rates and awareness of tsunami hazard maps are remarkably low, maps (particularly those published in Japan) present the threat from tsunamis simply as a type of risk information, and frequently do not serve as tools to support evacuation drills, although we can find a few preferable exceptions.

However, the interaction between human systems (evacuation behavior) and natural systems (tsunami behavior) should, by its nature, be the most important element in analyzing and improving tsunami evacuation (Sun et al. 2014a). There is a need for the interdisciplinary integration of research outcomes regarding human systems, obtained primarily from fields such as psychology, and research outcomes regarding natural systems, obtained primarily from fields such as tsunami engineering, that is there is a need for the creation and deployment of interfaces-interactive representation tools that visualize the interaction between both types of systems.

The importance of such interactions can be understood in terms of two standards. The first is a physical standard. Evacuation behavior is the outcome of complex human decision-making processes. However, on a fundamental level, if people's physical movement (human systems) and the tsunami's physical behavior (natural systems) overlap in time and space even once, evacuation fails, while if they remain separate, evacuation succeeds. The interaction between human systems and natural systems during tsunami evacuations thus registers first against this physical standard. Two systems interact at first, neither psychologically nor socially, but, just physically and materialistically, resulting in a crucial difference, either life or death.

The second is a psychological or societal standard. This standard is expressed in phrases often repeated in relation to tsunami evacuation, such as "carelessness," "giving up," "waiting for information," "everyone for themselves," "going down together," and "leaving others to die." For example, people whose houses are shown on a hazard map as being outside the inundation zone may become "careless," while those whose houses are shown as being at extreme risk may "give up." When a tsunami actually approaches, people tend to wait for information and wonder if they really need to evacuate right away (Yamori 2014), although based on recent studies, how 
quickly people respond to early warning of tsunami varies widely (Lindell et al. 2015; Fraser et al. 2016; Wei et al. 2017). Even if they are instructed to protect their own lives from the threat of a tsunami by following an "everyone for themselves" principle, many feel unable to "leave family members to die" and therefore await help while accepting that they may all "go down together" (Yamori 2014; Goltz 2017). All these realities reflect the fact that phenomena arising in human systems affect (understanding of) phenomena arising in natural systems, and vice versa. This is why we argue that interactions between the two systems, as observed through psychological and societal standards, hold the key to effective evacuation countermeasures.

This study focuses on evacuation behavior during tsunamis, which since the 2011 Great East Japan Earthquake and Tsunami have been viewed as the most important disaster prevention issue currently facing Japanese society (Committee for Technical Investigation on Countermeasures for Earthquakes and Tsunamis Based on the Lessons Learned from the "2011 off the Pacific Coast of Tohoku Earthquake" 2011), with a special attention to the betterment of evacuation drills. We first describe the Nige-Tore (pronounced "nigay-toray") smartphone app for evacuation drills, which was developed by the authors, to improve conventional group evacuation drills, in which participants evacuate together as a group to the same designated place by following a prescribed scenario (Sect. 2.1). We then explain how this app serves as an interactive representation tool that enables potential tsunami evacuees to individually visualize the interrelationship between human systems and natural systems, thus providing the key to analyzing and improving evacuation behavior (Sect. 2.2). We next discuss "commitment" and "contingency" as key concepts to describe the effectiveness of the Nige-Tore app and its advantages over previous evacuation measures and methods, such as the use of hazard maps and group evacuation drills (Sect. 3). Finally, we point out the importance of the synergistic effects that Nige-Tore creates between commitment and contingency in preparing for unforeseen events, and summarize the study (Sect. 4).

\section{Nige-Tore: A Smartphone App for Evacuation Drills}

We developed the Nige-Tore smartphone app for evacuation drills from the perspective outlined above. Here we provide only a simple overview of the latest version of Nige-Tore, with a focus on points closely related to the arguments made in this article. We also describe how NigeTore serves as a tool that enables individual tsunami evacuees to visualize the interrelationship between human systems and natural systems, which holds the key to analyzing and improving evacuation behavior.

\subsection{Overview and Main Functions}

By utilizing the Global Positioning System (GPS) functions of smartphones, the Nige-Tore app simultaneously displays on the smartphone screen images of both the real-world movements of the participant holding the smartphone during an evacuation drill and the projected spatial and temporal changes in tsunami inundation, based on the Central Disaster Management Council $(2012,2013)$ worstcase scenario for a Level 2 tsunami caused by a large earthquake in the Nankai Trough. The app allows users to view these images both in real time and after the fact. The user is constantly informed, during a drill, of "success" or "failure" of the evacuation, whether or not the user can keep distance from the simulated tsunami approaching behind him/her, based on a calculated positional relationship between the user and the frontline of tsunami inundation. We describe the system configuration and main functions of the Nige-Tore app by dividing them broadly into three stages and describing the screen changes that occur on the user's smartphone.

The first stage is the "initial set-up and hazard map confirmation" stage. After the top page is displayed, a page requesting input of the evacuation start time-an important initialization condition-appears (Fig. 2). The amount of time required between sensing an earthquake and beginning evacuation varies widely among individuals (depending on factors such as their age) and situation (depending on factors such as whether they evacuate alone, help a coresident with difficulty walking to evacuate, or call on neighbors to evacuate). The length of this interval is one of the biggest factors determining evacuation success or failure and is one that evacuation drill participants are able to change during emergencies. For these reasons, users are allowed to freely set the start time for their evacuation, for example, at $15 \mathrm{~min}$ or $60 \mathrm{~min}$ after the earthquake. In Fig. 2, the time has been set at $110 \mathrm{~min}(1 \mathrm{~h}$ and $50 \mathrm{~min})$, because a tsunami is projected to arrive in the selected location (northern Sakai, in the greater Osaka metropolitan area) approximately this long after the earthquake, and we have assumed that the user will spend a certain amount of time on relief activities before evacuating.

Next, a map of the surrounding area automatically appears on the screen, based on the location where the Nige-Tore app was launched (determined using GPS location data collected by the smartphone) (Fig. 3). The screen shows the current location of the individual who launched the app (the blue circle in the center of the screen), the projected inundation zone for the surrounding area (lighter blue zone for shallower and darker blue zone 


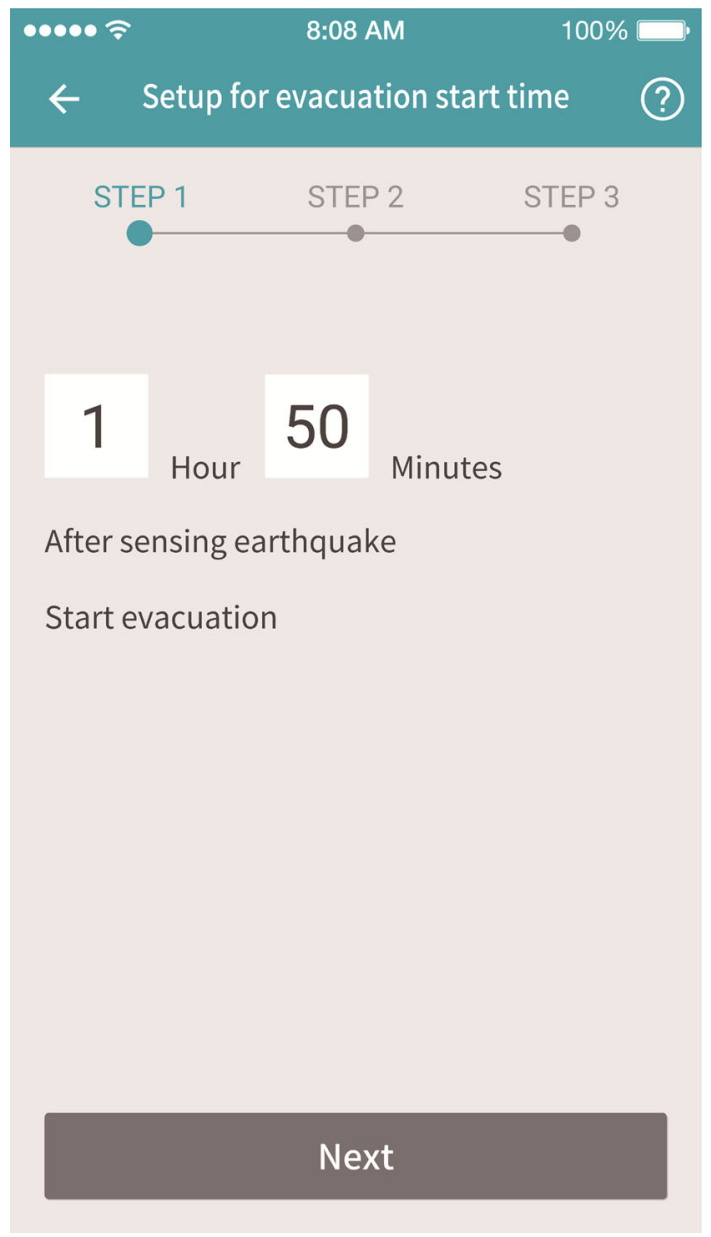

Fig. 2 Opening set-up page of the Nige-Tore smartphone app that requests input of the evacuation start time that is required between sensing an earthquake and beginning evacuation

for deeper inundated), and evacuation sites designated by the municipal government, such as elevated locations and tall evacuation buildings (green circles). This screen is equivalent in terms of content to conventional tsunami hazard maps. Nige-Tore can provide hazard map information-which is typically only available to local residents-to tourists and other temporary visitors in a given area (an English version of the app has being created), and presents the information at the relevant location.

The second stage is the "drill" stage. When the user presses the "Start Drill" button in Fig. 3, a screen similar to that in Fig. 4 appears. In our example, the screen shows that the user has moved from the left of the screen to the right during the drill. This movement record is displayed as the trajectory of a continuous series of dots that tracks the user's movements. At this point in the drill, the color of the dots is red, but depending on the amount of time left before the tsunami is expected to reach the user's current location, it changes from green (outside the inundation zone), to yellow-green (in more than $30 \mathrm{~min}$ ), yellow (in

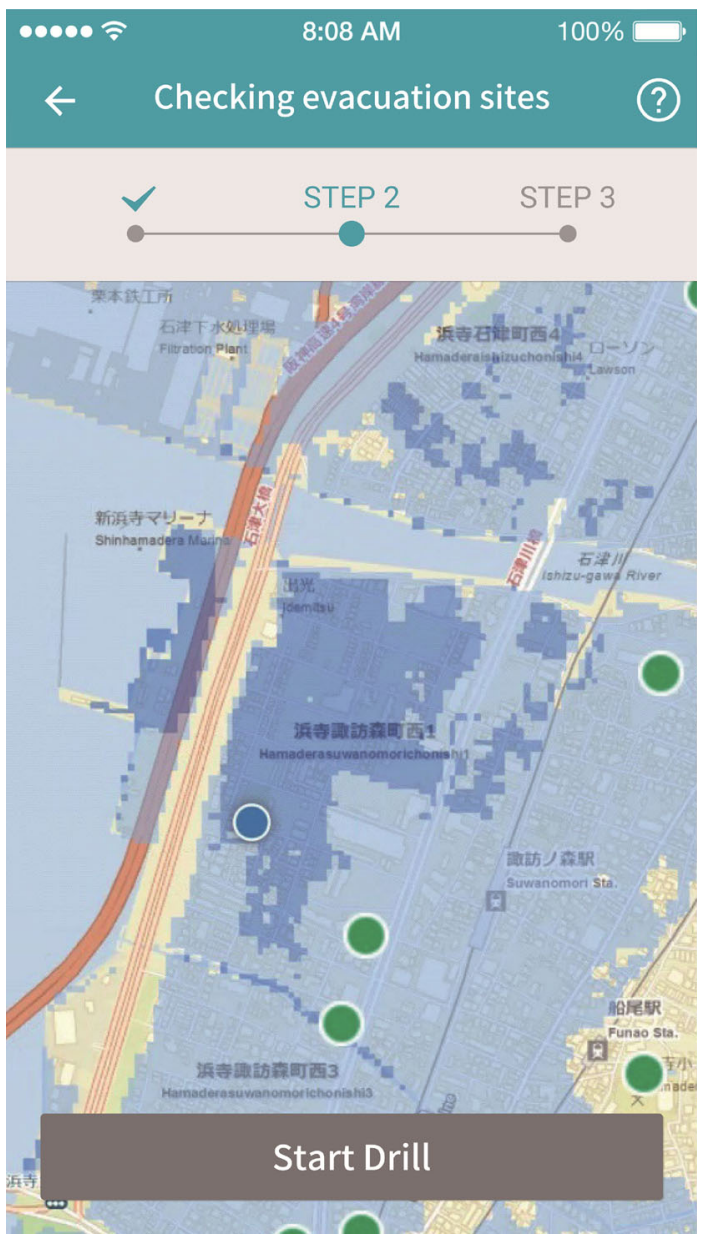

Fig. 3 Initial page of the Nige-Tore smartphone app that shows the user's current position (blue circle in the center of the screen), the maximum inundated area (light blue), deeper inundated area (dark blue), and evacuation sites (green circles)

15-30 min), orange (in 5-15 min), red (in less than $5 \mathrm{~min}$ ), or black (the tsunami has reached the user). When the dots turn red or black, a voice also announces the situation. Announcement is made only in Japanese, but, an English of the app is now being created.

The screen in Fig. 4 also displays the precise amount of time remaining before the tsunami is expected to arrive ( 3 min $24 \mathrm{~s}$ ), the time elapsed since the earthquake ( $1 \mathrm{~h}$ $51 \mathrm{~min} 36 \mathrm{~s}$ ), and the anticipated depth of the tsunami at the user's current location $(3 \mathrm{~m})$. The screen also displays the extent of tsunami inundation at that point in time in darker blue (in Fig. 4, inundation has begun along the ocean shore on the left of the screen and the riverbank at the top), and this zone steadily expands as a moving image. Figure 5 shows the screen as it appears when the user has reached a safe area (outside the inundation zone). Here, the user has evacuated from the top left of the screen toward the center. The color of the dots that shows the user's location at various points in time has changed from the 


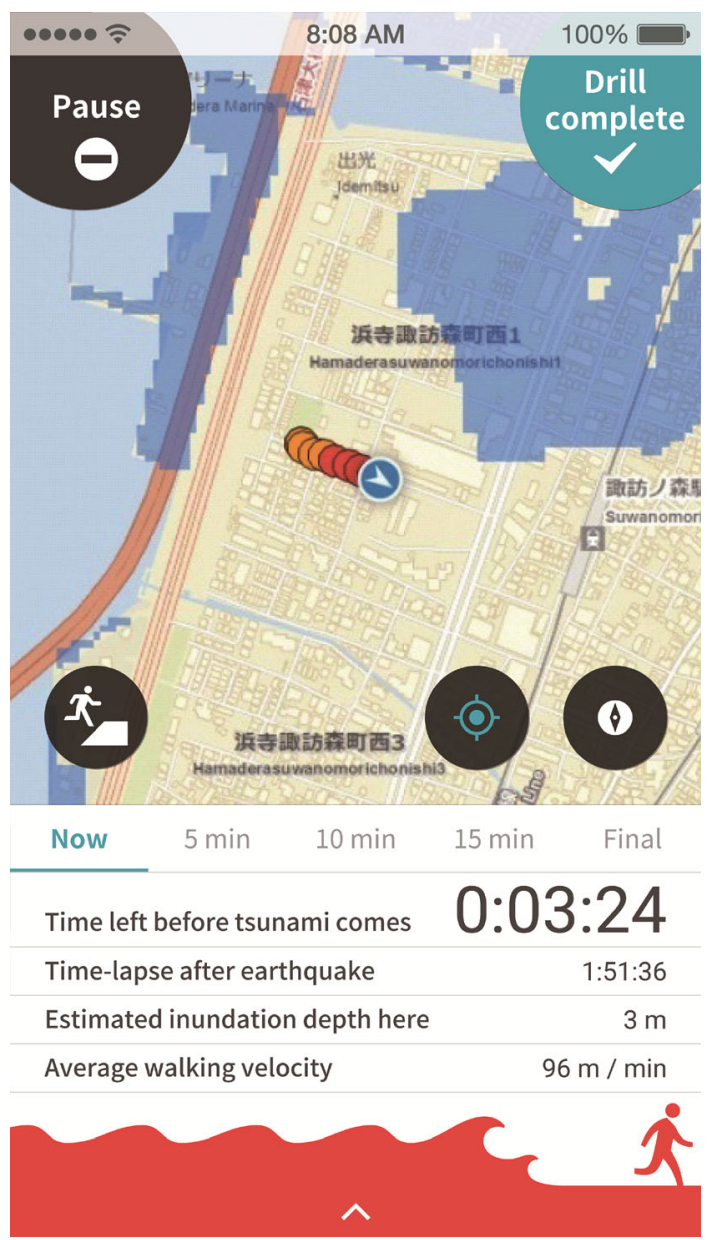

Fig. 4 A sample page of the Nige-Tore smartphone app during an evacuation drill in which a user is moving from left to right on the screen to escape from a tsunami coming from both the left (sea) and the upper (river) sides

initial red, to orange, to yellow, to yellow-green, and finally to green.

This whole system allows the user to continuously monitor the relationship between their current location (evacuation behavior) and the advancing tsunami during the evacuation drill. It should be noted that even if the evacuation fails (a black dot is displayed), the user can continue the drill, and the app continues to operate as intended.

The third stage is the "rating and reflection" stage. When the user determines that they have completed the evacuation drill, they press the "End Evacuation" button. The results of the drill then appear on the screen. First, the screen displays the success or failure of the drill according to three levels: "Succeeded" (evacuation completed with at least $5 \mathrm{~min}$ of leeway before inundation at any stage during the drill); "Imminent Danger" or "Barely Escaped" (evacuation succeeded, but leeway dipped below 5 min at its lowest point); and "Failed." This system was designed

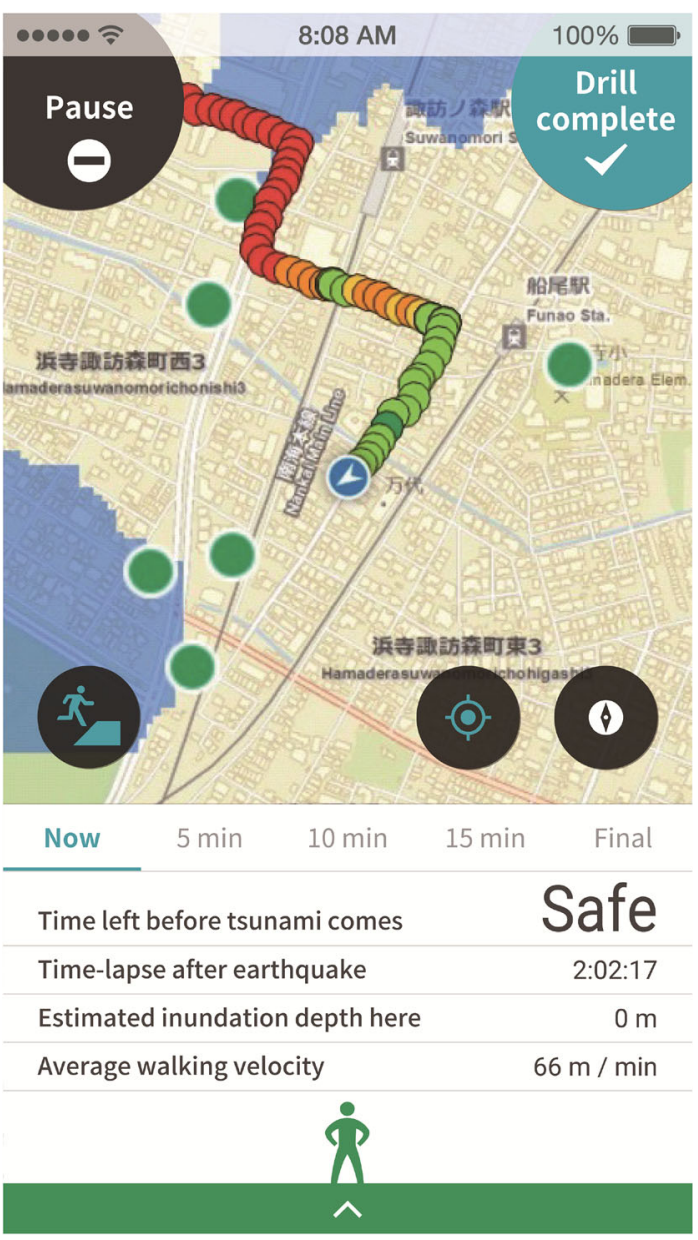

Fig. 5 A sample page of the Nige-Tore smartphone app during an evacuation drill in which a user has escaped from more dangerous conditions (red, orange, and yellow dots) and reached a safer zone (green) outside of the inundation

to compensate for the most significant weakness of conventional evacuation drills, which is that they do not indicate in practical terms whether the participant has succeeded or failed.

The user is able to view the full details of the drill, specifically their trajectory of movement overlaid with changes in tsunami inundation over time, from the start to the end of the drill. This is presented as a continuous video made up of situation maps such as those shown in Figs. 4 and 5. This enables drill participants to understand the relationship between their own evacuation behavior and the state of tsunami inundation over time, via a map. Using the same video, the user can set the start time for the evacuation hypothetically, adjusting it to be either earlier or later than they set it during the actual drill (for example, selecting "If I started evacuation $10 \mathrm{~min}$ earlier"), and view a simulation of what would have happened in that situation. This "rating and reflection" data can be saved in 
a "Drill Album" on their smartphone, and can be compared with the results of future drills.

\subsection{Interactions Between Human Systems and Natural Systems}

Let us examine three particularly important points from the overview of the Nige-Tore app. All three of these points illustrate how Nige-Tore functions effectively as a tool for expressing the interactions between human systems and natural systems by visualizing both of these systems simultaneously.

First, it is important that the Nige-Tore app encourages drill participants to independently choose and take action regarding their evacuation destination, route, and start time in relation to the time at which the earthquake occurred (for instance, by making decisions such as "I will probably need $30 \mathrm{~min}$ to prepare for evacuation with my elderly coresident"), which are key factors in determining the success or failure of evacuation. These factors have literal life-or-death importance during an actual tsunami evacuation, especially when evacuating individually, and for this reason, they tend to give rise to indecision or inner conflict in evacuees. Regardless of this fact, conventional group evacuation drills, in which participants evacuate together as a group to the same designated place by following a prescribed scenario, provide no leeway whatsoever for participants to make independent decisions regarding these factors.

Second, Nige-Tore overlays individual evacuation behavior (a record of movement through the landscape), which is the output of the user's independent decisions and behaviors, with projected changes over time in tsunami inundation in the area where the drill is taking place. This enables drill participants to understand, moment by moment, the changing relationship between their movements and the tsunami inundation, for instance by seeing whether their movements over the past several minutes have distanced them from the tsunami or not. This means that the Nige-Tore app does not simply present information about these two systems-human and natural-side by side; rather it presents information that expresses the interactions or relationship between the two systems.

Third, Nige-Tore presents this information about interactions and their changes over time to users in a way that makes a strong impression. The app's simulation function enables users to check, after the fact, whether their evacuation would have succeeded or failed under different conditions, for instance if they left their house $10 \mathrm{~min}$ later or earlier. While the government's published worst-case tsunami scenario (Level 2) is used for the app's basic setting, users in some areas (Chiba Prefecture) can select inundation simulations based on different scales of tsunami (including Level 1). We plan to add this feature for users in all areas in the future.

By using these functions, users can access almost unlimited possible interactions between human systems and natural systems (scenarios). Thus, the Nige-Tore app does not simply visualize the one situation that actually occurred in this particular drill-although that alone is a function that almost no training methods or tools have provided in the past-but also communicates to the user the possibility of transforming these interactions (their diversity).

\section{Interactions Between Commitment and Contingency}

We discuss the effectiveness of Nige-Tore app based on "commitment" and "contingency" as key concepts. In Sect. 3, "commitment" and "contingency" are introduced to describe the effectiveness of the Nige-Tore app and its advantages over previous evacuation measures and methods, such as the use of hazard maps and group evacuation drills.

\subsection{Characters Versus Players and Commitment Versus Contingency}

In the above sections, we have described the Nige-Tore app's effectiveness as a tool for tsunami evacuation drills, and in particular its expected advantages over previous group evacuation drills, from the perspective of interactions between human systems and natural systems. We also suggested that this effectiveness may stem from the fact that the app does not simply present the interactions between these two systems, but rather shows users the potential for transforming these interactions (it shows that other outcomes are possible). In this section, we will focus on this last point and deepen our consideration of the NigeTore app's effectiveness.

When considering this point, Azuma's (2007) arguments regarding "characters" and "players" are extremely useful. This insightful discussion examines the typical characteristics of contemporary human life in a postmodern society with a subculture consumption style typified by light novels, bishōjo games (gal games, a type of Japanese video game), and similar cultural phenomena, such as "choose your own adventure novels" and "tabletop role-playing games" (like Dungeons and Dragons). "Characters" and "players" are core concepts within Azuma's argument. The important point in relation to the present study is that many of these novels and games are structured so that the choices of the reader or player give rise to multiple branches in the story, and multiple outcomes exist depending 
on which branch is pursued-they have so-called "multiscenario" or "multi-ending" structures.

The word "character" expresses the tendency for an individual to immerse him- or herself in a specific scenario that they are actualizing within such a game, and originates in the "characters" (or reader or player who identifies with the character) living under a single set of unchangeable limiting conditions (at least for the present moment) that represent one given branch within the branching-scenario game. In contrast, the word "player" expresses the tendency to take a bird's-eye view of the totality of diverse scenarios that may branch off in various directions, and originates in readers or players who relativize each branch as one possibility of many, taking the perspective of a player looking down on the entirety of a world comprised of multiple possible scenarios.

While the character/player concept suggests important insights for the present study, there is also a danger of interpreting Azuma's ideas in connection with their immediate context (subculture theory), and for that reason we will generalize them using the terms "commitment" and "contingency." Defined in light of the argument presented thus far, these concepts are as follows. First, "commitment" (devotion, involvement, or responsibility) refers to the act of immersing oneself in and viewing as absolute one particular scenario or its potential to be actualized, given conditions in which infinite scenarios may be actualized depending on the interactions between human systems and natural systems. "Contingency" thinking (an accidental, incidental, or temporary state) refers to the act of relativizing and separating oneself from any particular scenario or its potential to be actualized, given the same conditions.

\subsection{How the Nige-Tore App Enhances both Commitment and Contingency}

The core concepts of commitment and contingency can be used to more clearly position the effectiveness of NigeTore as outlined in Sect. 2, and particularly Sect. 2.2. The Nige-Tore app functions to enhance both commitment and contingency thinking.

We will first describe how Nige-Tore enhances commitment. During trials of the Nige-Tore app conducted with community members and students, we received the following comments on questionnaires distributed after the drills (free response section) and in interviews with participants: "I felt tense," "I felt danger because I knew how many minutes I had until the tsunami got to me," "I felt a sense of reality and urgency because the tsunami was coming closer," "I liked knowing the results clearly," "No matter how much I ran, the tsunami kept bearing down on me and I felt like I might die," "I took a road near the ocean and I was surprised when the tsunami came close to me" (for a detailed report on the study, see Sugiyama et al. 2016). Trials have been conducted with over 5000 participants in a wide geographical area including Chiba, Shizuoka, Aichi, Wakayama, Osaka, and Kochi Prefectures.

All of these comments were made in relation to evacuation behaviors and outcomes that occurred under conditions selected by participants in trial drills using the Nige-Tore app and suggest stronger levels of commitment among participants in comparison with conventional evacuation drills. Feelings of tension, reality, and urgency can be interpreted as resulting from this commitment. The indirect basis for these feelings is the "lack of tension" felt during conventional evacuation drills. In many cases, group evacuation drills carried out in the past have not determined how close the imagined tsunami has come, nor have they calculated the time needed for evacuation behavior or preparation. As a result, the drills have been implemented without clear knowledge of whether the evacuation behavior was ultimately appropriate or not. The drills have not created scenarios in which participants were able to "commit" with the maximum possible sense of tension, reality, and urgency.

However, we are not arguing that the strong commitment likely engendered by the Nige-Tore app drills has an unconditionally positive impact on evacuation drill participants. This is well expressed in an evaluation of the Nige-Tore app (Ushiyama 2016) that pointed out that depending on the situation, it can also be a tool that gets people killed. Strongly committing to a one-time trial implemented under a certain set of conditions or to the outcomes of that trial also means disregarding the possibility that other scenarios might arise. If drill participants ignore the infinite "ifs"- "If I had taken a different street," "If the actual tsunami is bigger"-and waver between hope and despair based on only the results indicated by the Nige-Tore app (if Nige-Tore is used in a way that compels this type of usage), then this criticism will likely become reality.

Next, we will explain how the Nige-Tore app enhances contingency thinking. The following example was observed at an evacuation drill using Nige-Tore. Following this drill, both data gathered through the Nige-Tore app (videos recorded on smartphones) and videos filmed at the training site were viewed by a community study group that included not only participants who had used the app themselves during the drill, but also other local residents. During this workshop, participants (including those who had participated in the drill) made many comments such as "If I had left the house a little earlier..." and "If that concrete-block wall had crumbled..." These comments indicate that compared to conventional evacuation drills, drills using the Nige-Tore app enable participants to 
relativize and distance themselves from particular scenarios and the possibility of their occurring - that is, the participants distance themselves from the evacuation behavior that they actually enacted, and contingency thinking is enhanced.

However, as with commitment, we are not arguing that these results and the contingency thinking encouraged by the Nige-Tore app have unconditionally positive impacts. This is well expressed in the comment of one participant, who said, "It has a strong game-like feeling, and tension may disappear." Nige-Tore encourages drill participants to adjust various human- and natural-system conditions (such as trying a different route or seeing what happens under a different tsunami prediction), and confirm, for example, that in contrast to their experience during the drill they may be able to escape effectively under the new set of conditions. This is an important function in guiding people toward contingency thinking in a positive sense. However, from a different perspective, this also means that the NigeTore app has a game-like structure to it, and the above comment indicates a negative aspect of the quality, possessed by games, of being able to "start over" or "redo" the evacuation.

\section{Synergistic Effects of Commitment and Contingency: Preparing for "Unforeseen Events"}

In Sect. 4, we point out the importance of the synergistic effects that Nige-Tore creates between commitment and contingency thinking in preparing for unforeseen events. Positive synergistic effects between commitment and contingency thinking on tsunami evacuation are closely related to an adaptive learning process in rapidly changing conditions, which is particularly important in preparing for unforeseen events, a term that has been widely used since the Great Japan Earthquake and Tsunami.

\subsection{What Does It Mean to Prepare for "Unforeseen Events"?}

The Nige-Tore app can simultaneously engender actions based on both commitment and contingency thinking. However, both types of actions have merits or advantages as well as demerits or disadvantages. In addition, at first glance these two types of actions appear to be oriented in opposite directions and to exist in an inverse relationship so that each cancels out the other (the former absolutizes a particular scenario while the latter relativizes it). However, in reality this is not the case; the two have a synergistic relationship in which each one aids and strengthens the other. In this section, we consider this important point in light of preparation for "unforeseen events"-a term that has been in vogue since the Great East Japan Earthquake and Tsunami-and summarize the findings of this study.

The concept of "unforeseen events" (called "sotei-gai" in Japanese) became a major topic in discussions surrounding the prediction of and societal response both before and after the 2011 Great East Japan Earthquake and Tsunami (Hosomi 2011). However, the term is rapidly being forgotten, as is often the case with trendy phrases. This is because it was typically tossed about in everyday settings, without making the effort to uncover its theoretical meaning. We must first critically consider statements such as, "In the future, we will take unforeseen events into consideration as we prepare for disasters." Declarations of this sort do no more than express a recognition that preparing for unforeseen events is important, while saying nothing about how that can be achieved. Alternatively, they express a simple self-contradiction in which the speaker asserts he/she will foresee scenarios or possibilities that he/ she is not in fact able to foresee.

Next let us consider the current orthodox attitude toward unforeseen events, which is to utilize a strategy of "considering all scenarios and possibilities that we are able to think of." This includes strategies that attempt to take into account even worst-case damage scenarios and the largest conceivable tsunamis and earthquakes, including those that would ordinarily be considered beyond the realm of possibility. This is also the basic strategy adopted by the Japanese government when facing a coming Nankai Trough earthquake. At first glance, such attitudes are important and unproblematic.

However, on reflection, we see that these strategies do not prepare for unforeseen events, but rather the opposite: they lay the groundwork for being caught off guard. This is because it is precisely the feeling of omnipotence or comprehensiveness that arises from considering all conceivable scenarios and the likelihood of their occurring, and from fully subsuming oneself in the scope of consideration that forms the precondition for the strong feeling of surprise and unexpectedness when an unforeseen event not included in the scenarios does in fact occur.

\subsection{Relativization and Its Pitfalls}

Compared to the naïve understandings of unforeseen events mentioned above, it is worth focusing on certain aspects of the strategy proposed by Hatamura (2011, p. 150), who is well known in the field of failure analysis: "Become a 'malicious devil' and meticulously [...] bring to light dangerous scenarios." In particular, if we broadly interpret and amplify these words of Hatamura to say, "Become a 'malicious devil' and endlessly search for unforeseen 
scenarios," the differences between this and conventional strategies become clear.

The core of this strategy is "relativization." In contrast to deciding that a particular approach is best, or that one has thought of all possible scenarios, this strategy encourages us to constantly attempt to step beyond any given decision; it is precisely the unending continuation of this postmodern relativization that comprises preparation for the unforeseen. All of the strategies that we have called "naïve" assume the existence of a final state (an ideal state) in which, if certain actions are taken, one will have prepared for the unforeseen. However, this does not represent preparation for the unforeseen but rather its source-a hotbed of the unforeseen. The true essence of preparing for the unexpected lies in the actions of the "malicious devil" who constantly confronts the unforeseen through repeated relativization. This awareness represents a clear step forward.

However, this relativization also contains a pitfall. This pitfall arises from the fact that the repetition of the relativization leads to its wearing away. Relativization consists of the "malicious devil" continuously asking questions such as "Can you really say this is the best option?" and "There are surely other scenarios, aren't there?" This is none other than the process of being repeatedly reminded that one's assurance in having found the absolute right answer was merely false hope. This repetition eventually leads to an attitude in which one thinks, "Well, this idea (or this drill), too, is sure to be proved wrong at some point." In this way, relativization loses its power.

How, then, can this power be maintained? The answer may sound paradoxical, but the key lies in viewing the scenario (set of assumptions) at hand as absolute, fully believing in it with a sense of omnipotence that "finally, I've gained a complete picture," and temporarily immersing oneself in and refining that scenario. In order to achieve relativization, we must first absolutize. This is because the loss of power described above stems from doubting a particular scenario from the start (telling oneself that "Anyway, this time will be no good either..."). The necessary precondition for the sense of having encountered a fresh unforeseen scenario-for thinking to oneself, "Wow, I hadn't thought of that possibility"-for the shock of having one's expectations betrayed in a positive sense, is being able to temporarily but completely immerse oneself in a particular scenario (in the case of evacuation drills, a set of drill conditions).

The above argument can be logically restated using the key concepts of this article-commitment and contingency. Preparing for the unforeseen does not consist of arriving at a state in which one can convince oneself that unforeseen scenarios no longer exist. Rather, the essential action is one of continuously and proactively experiencing and encountering different unforeseen events. This can be more effectively achieved through the coexistence of two types of actions that at first glance appear to be oriented in opposite directions. One is based on contingency thinking, in which, every time one begins to assume that the present scenario is the only one or begins to feel that one is omnipotent and has thought of all possibilities, one becomes the "malicious devil" who relativizes that scenario, thereby distancing oneself from it. However, for this process of relativization to continue indefinitely without losing its power, it is necessary to compliment contingency thinking with its polar opposite, commitment. For relativization to retain its vitality, one must first view a given scenario and the possibility of its actualization as absolute, and fully immerse oneself in it-that is, commit to it. Preparing for the unforeseen requires that we maintain an attitude of both commitment and contingency simultaneously at a high level—or that we allow them both a broad scope.

\section{Conclusion: The Ability to Prepare for "Unforeseen Events"}

To borrow the phrasing of Azuma (2007), people who participate in evacuation drills using the Nige-Tore app are encouraged to immerse themselves as "characters" in a particular scenario and the possibility of its actualization, and strongly commit to it. When participants complain that "My evacuation failed even though I tried so hard," they are strongly committing to the scenario. However, and precisely because of this commitment, they are also able to think, "I wonder if things would have been different if only I had left 5 min earlier," thus profoundly experiencing, as "players," the importance of distancing themselves from the present scenario through contingency thinking. Through this process of endlessly taking action to approach an overall picture of the possible world that contains endless scenarios and possibilities, users of the Nige-Tore app are able to actively explore, consider, and experience the meaning of their own decisions and actions-that is, the meaning in terms of the interaction between human systems and natural systems. This is the power to be able to prepare for unforeseen events.

The effectiveness of the Nige-Tore app derives from the fact that it is a tool for appropriately expressing the interactions between human systems and natural systems, which hold life-or-death importance for analyzing and improving evacuation behavior. The Nige-Tore app has the ability to display a certain scenario-which has occurred due to interactions between human systems and natural systemsto the user in a way that makes a deeper impression than a conventional evacuation drill. But if that were all it did, its 
function would be limited to generating commitment to that one scenario.

However, the Nige-Tore app has the additional ability to show users the other possible interactions between human systems and natural systems; that is, it can show users that even though a certain scenario played out this time, many other possible scenarios and outcomes exist. Thus, the app also presents contingencies. The effectiveness of the NigeTore app stems from the fact that it is an interface that enables commitment and contingency thinking to coexist and synergize with one another. It therefore lays the foundation for developing the ability to truly prepare for unforeseen events.

Finally, evacuation drills with the Nige-Tore app need to be improved and expanded mainly in two directions. First, the app is now being expanded further to a group of individuals interacting mutually. A new computer-based system is expected to demonstrate graphically simulated collective behavior of drill participants, who participated in a Nige-Tore drill originally on an individual base, by aggregating computationally all the related data in a NigeTore data server, which were stored every time an evacuation drill is conducted with the app. The outcome graphics will be helpful to estimate what kinds of collective phenomena, like an evacuation congestion, might occur, and where.

Second, empirical assessments of Nige-Tore's effectiveness should be made more comprehensively, with carefully constructed quantitative data, to show how the Nige-Tore app improves conventional styles of tsunami evacuation drills. When an empirical assessment is made, an experimental design that compares a treatment group (evacuation drill participants who used Nige-Tore) versus a control group (evacuation drill participants who did not) is also needed. Additionally, findings in research on training and instructions, such as Kirkpatrick and Kirkpatrick's (2016) evaluation criteria of, reaction, learning, behavior, and results, and Ford and Schmidt's (2000) idea for improving emergency trainings, would be useful for setting a reliable criterion upon which the Nige-Tore app's effectiveness is tested.

An adaptive learning process in rapidly changing conditions, which Ford and Schmidt (2000) emphasized, is particularly important in Nige-Tore's evaluation, because Nige-Tore also aims at not only routine expertise, but also adaptive expertise of coping flexibly with unforeseen events in a real emergency. Positive synergistic effects between commitment and contingency on tsunami evacuation, generated by Nige-Tore trainings, are closely related to what Ford and Schmidt (2000) proposed for significant components of emergency response training, which are discovery learning, error-based learning activities, and metacognitive skills.
Acknowledgments Nige-Tore is a smartphone app developed by the Nige-Tore Development Team (representative: Katsuya Yamori), and is a registered trademark. The app was developed with support from the Enhancement of Societal Resiliency against Natural Disasters Program of the Cabinet Office's Council for Science, Technology and Innovation SIP (Cross-ministerial Strategic Innovation Promotion Program) (Supervising entity: Japan Science and Technology Agency). The authors of this article express their sincere gratitude for this support.

Open Access This article is licensed under a Creative Commons Attribution 4.0 International License, which permits use, sharing, adaptation, distribution and reproduction in any medium or format, as long as you give appropriate credit to the original author(s) and the source, provide a link to the Creative Commons licence, and indicate if changes were made. The images or other third party material in this article are included in the article's Creative Commons licence, unless indicated otherwise in a credit line to the material. If material is not included in the article's Creative Commons licence and your intended use is not permitted by statutory regulation or exceeds the permitted use, you will need to obtain permission directly from the copyright holder. To view a copy of this licence, visit http://creativecommons. org/licenses/by/4.0/.

\section{References}

Azuma, H. 2007. The birth of game-like realism (Gemu teki riarizumu no tanjou). Tokyo: Kodansha (in Japanese).

Cabinet office, Government of Japan. 2015a. Disaster management in Japan. http://www.bousai.go.jp/1info/pdf/saigaipamphlet_je.pdf. Accessed 3 Mar 2019.

Cabinet Office, Government of Japan. 2015b. Special report: Promoting tsunami preparedness (Tokubetsu houkoku: Tsuanmi bousai wo susumeru tameni). Bousai 80: 4-7 (in Japanese).

Central Disaster Management Council. 2012. Report of the working group on tsunami evacuation measures (Tsunami hinan taisaku ni kansuru wakingu gurupu repoto). Tokyo: Working Group on Tsunami Evacuation Measures, Committee for Policy Planning on Disaster Management, Central Disaster Management Council. http://www.bousai.go.jp/jishin/tsunami/hinan/pdf/report.pdf. Accessed 10 Jan 2018 (in Japanese).

Central Disaster Management Council. 2013. Countermeasures against a Nankai Trough Earthquake: Final report (Nankai torafu jisin taisaku: Saishu houkoku sho). Tokyo: Working Group on Countermeasures Against a Nankai Trough Earthquake, Committee for Policy Planning on Disaster Management, Central Disaster Management Council. http://www.bousai.go.jp/ jishin/nankai/taisaku_wg/pdf/20130528_honbun.pdf. Accessed 10 Jan 2018 (in Japanese).

Committee for Technical Investigation on Countermeasures for Earthquakes and Tsunamis Based on the Lessons Learned from the "2011 off the Pacific Coast of Tohoku Earthquake". 2011. Report of the committee for technical investigation on countermeasures for earthquakes and tsunamis based on the lessons learned from the "2011 off the Pacific coast of Tohoku Earthquake". http://www.bousai.go.jp/kaigirep/chousakai/toho kukyokun/pdf/Report.pdf. Accessed 3 Mar 2019.

Ford, J.K., and A.M. Schmidt. 2000. Emergency response training: Strategies for enhancing real-world performance. Journal of Hazardous Materials 75(2-3): 195-215.

Fraser, S.A., E.E. Doyle, K.C. Wright, S.H. Potter, J. McClure, D.M. Johnston, G.S. Leonard, M.A. Coomer, et al. 2016. Tsunami response behaviour during and following two local-source 
earthquakes in Wellington, New Zealand. International Journal of Disaster Risk Reduction 16: 123-133.

Goltz, J. 2017. Tsunami tendenko: A sociological critique. Natural Hazards Review 18(4). https://doi.org/10.1061/(asce)nh.15276996.0000254.

Hatamura, Y. 2011. Unprecedented and unforeseen: Learning from the Great Eastern Japan Earthquake (Mizou to souteigai: Higashi nihon daishinsai kara no kyoukun). Tokyo: Kodansha (in Japanese).

Hosomi, M. 2011. Safety and security of Japanese society threatened by unpredictable earthquake and tsunami: Overcoming the crisis with Japanese wisdom and cheer. Clean Technologies and Environmental Policy 13(3): 415-416.

Japan Meteorological Agency. 2013. Start of new tsunami warning operation. https://www.data.jma.go.jp/svd/eqev/data/en/tsunami/ tsunamiwarning-leaflet.pdf. Accessed 3 Mar 2019.

Kirkpatrick, J.D., and W.K. Kirkpatrick. 2016. Kirkpatrick's four levels of training evaluation. Alexandria, VA: ATD Press.

Lindell, M.K., C.S. Prater, C.E. Gregg, E. Apatu, S.-K. Huang, and H.-C. Wu. 2015. Households' immediate responses to the 2009 Samoa earthquake and tsunami. International Journal of Disaster Risk Reduction 12: 328-340.

Sugiyama, T., Y. Sun, F. Lee, K. Yamori, S. Suzuki, T. Nishino, and K. Urabe. 2016. Development and challenges of tsunami evacuation drills using smartphone apps (2): Verifying the benefits of evacuation drills using the Nige-Tore app (Sumatofon wo tsukatta tsunami hinan kunren shien apuri no kaihatsu (2): Nige-Tore wo katsuyou shita hinan kunren no kouka no kensho). In Proceedings of the 18th Conference of the Japan Society for
Disaster Information Studies, 23 October 2016, Tokyo, Japan, 124-125 (in Japanese).

Sun, Y., K. Yamori, and S. Kondo. 2013. Disaster education based on community of practice: A case study in Okitsu, Kochi Prefecture. Journal of Integrated Disaster Risk Management 3(1): 92-106.

Sun, Y., K. Yamori, and S. Kondo. 2014a. Single-person drill for tsunami evacuation and disaster education. Journal of Integrated Disaster Risk Management 4(1): 30-47.

Sun, Y., K. Yamori, R. Tanisawa, S. Kondo. 2014b. Consciousness of disaster risk and tsunami evacuation: A questionnaire survey in Okitsu, Kochi Prefecture. Journal of Natural Disaster Science 34(2): 127-141.

Ushiyama, M. 2016. Comments on the panel discussion on creating a field of studies focused on natural disaster evacuation (Shizen saigai kara no hinan ni kansuru paneru disukasshion deno komento). The 35th Conference of the Japan Society for Natural Disaster Science, 22 August 2016, Shizuoka Prefecture Earthquake Disaster Prevention Center, Shizuka, Japan.

Wei, H.-L., H.-C. Wu, M.K. Lindell, S.-K. Huang, H. Shiroshita, D.M. Johnston, and J.S. Becker. 2017. Assessment of households' responses to the tsunami threat: A comparative study of Japan and New Zealand. International Journal of Disaster Risk Reduction 25: 274-282.

Yamori, K. 2014. Revisiting the concept of tsunami tendenko: Tsunami evacuation behavior in the Great East Japan Earthquake. In Natural disaster science and mitigation engineering: DPRI reports, ed. H. Kawase, 49-63. Berlin: Springer Verlag. 